Arden-Close, E., Moss-Morris, R., Dennison, L., Bayne, L., \& Gidron, Y. (in press) The couples' illness communication scale (CICS): development and evaluation of a brief measure assessing illness-related couple communication British Journal of Health Psychology DOI: $10.1348 / 135910709 X 476972$

\title{
The couples' illness communication scale (CICS): development and evaluation of a brief measure assessing illness-related couple communication
}

\author{
Emily Arden-Close ${ }^{1}$, Rona Moss-Morris ${ }^{2}$, Laura Dennison ${ }^{2}$, Louise Bayne ${ }^{3}$, \& Yori \\ Gidron $^{4}$ \\ ${ }^{1}$ University of Sheffield, ${ }^{2}$ University of Southampton, ${ }^{3}$ Ovacome, the UK ovarian cancer \\ charity, ${ }^{4}$ Brunel University
}

\begin{abstract}
Objectives: When one member of a couple has a chronic illness, communication about the illness is important for both patient and partner well-being. This study aimed to develop and test a brief self-report measure of illness-related couple communication.

Design: A combination of correlations and multiple regression were used to assess the internal consistency and validity of the CICS.

Methods: A scale to provide insight into both patient and partner illness communication was developed. The Couples' Illness Communication Scale (CICS) was then tested on patients with ovarian cancer $(n=123)$ and their partners $(n=101)$, as well as patients with early stage multiple sclerosis who had stable partnerships ( $\mathrm{n}=64)$.

Results: The CICS demonstrated good acceptability, internal consistency, convergent validity (correlations with general couple communication and marital adjustment), construct validity (correlations with intrusive thoughts, social/family well-being, emotional impact of the illness and psychological distress), and test-retest reliability.

Conclusions: The CICS meets the majority of psychometric criteria for assessment measures in both a life-threatening illness (ovarian cancer) and a chronic progressive disease (multiple sclerosis). Further research is required to understand its suitability for use in other populations. Adoption of the CICS into couple-related research will improve understanding of the role of illness-related communication in adjustment to illness. Use of this short, simple tool in a clinical setting can provide a springboard for addressing difficulties with illnessrelated couple communication and could aid decision-making for referrals to couple counselling.
\end{abstract}


Research has indicated that chronic illness can have a considerable impact on partners, often leading to increased distress and reduced marital satisfaction (Berg \& Upchurch, 2007; Bogosian, Moss-Morris, Yardley, \& Dennison, 2009; Eriksson \& Svedlund, 2006). In particular, avoidance of discussing illness-related issues has been associated with worse outcomes for both partners (Manne, 1999; Manne et al., 2006). Examining this in detail, Manne et al. (2006), in a study of communication in couples coping with early stage breast cancer, found that demand-withdraw communication, defined as communication where one partner attempts to talk about an issue and the other withdraws, was associated with increased distress in couples dealing with a medical stressor, even if they reported high levels of marital satisfaction. This is important as even couples who have a good relationship in other respects may not discuss the patient's illness (Boehmer \& Clark, 2001; Holmberg, Scott, Alexy, \& Fife, 2001).

Qualitative studies suggest that couples who conceptualize a cancer diagnosis as a couple-related stressor talk about it openly, whereas those who view the disease of one partner as an individual stressor tend to avoid talking about the disease, leading to decrements in marital adjustment (Kayser, Watson, \& Andrade, 2007; Skerrett, 1998). This decreased adjustment_is not related to marital adjustment pre-diagnosis (Skerrett, 1998). In order to affect the transition from an 'I' awareness to a 'we' awareness (Skerrett, 2003), each partner should be aware of the story the other has constructed around the illness. Individuals who avoid talking about the illness to their partners may carry this strategy over to other people (Kayser et al., 2007). Even when this is not the case, lack of support by a partner cannot always be compensated for by support from other individuals (Pistrang \& Barker, 1995). Thus, clinicians working with patients with chronic illness should assess patients' perceptions of communication regarding the illness with their partners. Low levels of satisfaction with illness-related communication could warrant referrals to couple counselling. 
The evidence discussed above suggests that illness-related couple communication may not be equivalent to general couple communication, and as such questionnaires assessing couple communication i.e., the Communication Patterns Questionnaire, (Christensen, 1988) and the ENRICH couple scales (Fowers \& Olson, 1989) may not be appropriate for assessing illness-related couple communication. The content and meaning of illness may have specific intra-couple implications and effects on couple communication, independent of more general intra-couple communication issues. However, to date there is no widely accepted method of assessing illness-related couple communication. Lepore, Silver, Wortman, and Wayment (1996), have developed a five items scale to assess social constraints, which was tested on a sample of bereaved mothers, but could be adapted to refer to any traumatic event. However, this scale contains two questions which are not related to the event, and does not address whether the significant other is willing to discuss the event (rather than listening to the patient talk about it). This distinction is important as partner self-disclosure when discussing a cancer-related stressor has been associated with reduced general and illness-specific distress in patients (Manne et al., 2004). Similarly, 'we talk’ by the spouse, defined as a communal orientation to coping marked by the use of 'we' has been linked to health improvements in patients with heart failure (Rohrbaugh, Mehl, Shoham, Reilly, \& Ewy, 2008).

In addition, given that patients may not be willing and/ or able to fill in lengthy questionnaires, brief measures have recently been advocated in the literature as screening tools. Recent studies have demonstrated the utility of ultra-short instruments for screening of distress in chronic illness (Cohen et al., 2002; Gessler et al., 2008; Mitchell, 2007). Such instruments enable clinicians to quickly identify patients who may be in need of intervention, and reduce response burden on patients with health problems.

This research therefore had two aims: first, to develop a brief scale for assessing illness-related couple communication, and second, to test the psychometric properties of the 
scale. As the impact of an illness on couple communication is likely to vary depending on the nature of the illness and treatment, and the time in life at which it is diagnosed, it was decided to test the scale in both patients with a life-threatening disease (ovarian cancer) and their partners, and patients with a chronic progressive disease (multiple sclerosis). This was done as part of two separate randomized controlled trials with different ultimate outcomes. For example, intrusive thoughts were assessed in the ovarian cancer patients as there is evidence that posttraumatic stress symptoms are common in cancer patients. More generalized distress was assessed in the MS patients as they were enrolled in a trial to assess the effects of cognitive behavioural therapy on adjustment to early stage MS.

Ovarian cancer is most common in women aged over 50, and patients are often diagnosed at an advanced stage, due to non-specific symptoms, which means the survival rate is poor - currently five year survival in the UK is 38.9\% (Walters et al., 2009). Treatment is aggressive, usually consisting of six sessions of combination chemotherapy, and risk of recurrence is high. Thus, illness-related communication is likely to play a significant role in adjustment to the illness, particularly in newly diagnosed patients or those who have experienced a recurrence.

Multiple sclerosis (MS) is a demyelinating disease of the central nervous system. It is thought to affect around 2.5 million people worldwide and is often diagnosed in young to mid adulthood (National MS Society, 2008). For most patients, the disease is not life threatening unless they have the most progressive form of the illness. However, MS produces various unpleasant and potentially debilitating symptoms, including changes in sensation, muscle weakness and spasms, difficulty with moving, coordination and balance, problems in speech or swallowing, bowel and bladder dysfunction, visual problems, fatigue, pain syndromes, and sexual impairment (Graham, 2002; Mohr \& Cox, 2001). The course of the disease is unpredictable; around $85 \%$ of people are initially diagnosed with a relapsing-remitting form 
of the disease however for the majority of people, the disease becomes more progressive over time and impairment increases (Goodkin, 1998). Consequently, ongoing support and communication from significant others is likely to play a central role in adjustment to the illness. Overall, the inclusion of patients with both ovarian cancer and MS was considered to provide evidence for the generalisability of the scale across illnesses with different trajectories and levels of severity.

Study 1

Method

\section{Phase 1: construction of the Couples' Illness Communication Scale}

Construction of the Couples' Illness Communication Scale was originally based on insights gained from a pilot study conducted on 27 ovarian cancer patients. This study pretested an intervention which consisted of written emotional disclosure plus thirty minutes of stress management over the telephone, before and after which participants completed questionnaires assessing distress and quality of life. It was noted that participants who reported problems with family communication about their illness and lack of closeness to their partners experienced more distress, regardless of disease severity. This was explored further in a review of the literature addressing cancer in the context of marriage and measures developed to assess couple communication in healthy couples.

Individual items were developed based on the above and constructed into a 5-item self-report questionnaire. They covered two main domains: how comfortable the individual felt about discussing the illness with their partner and their impression of their partner's willingness/reluctance to discuss the illness. Differential phrasing of the items allows for the domains to be explored from both the patient's and the partner's perspective. Patients' views of their illness communication may differ from their partner's view and having both versions of the scale allows researchers to explore the effects of each of these on possible outcomes 
for both partners. The questions were designed by the first author and reviewed by the second author, a health psychologist with experience in working with patients with chronic illness and questionnaire development, with regard to content validity and wording. As a result of this process, one item was removed, and several minor modifications were made.

\section{Scoring and interpretation}

Items are scored on a five point Likert scale from 1 (strongly disagree) to 5 (strongly agree). Items 1 'It is hard for me to express feelings about my illness to my partner' and 3 'My partner is reluctant to talk about my illness' are reverse scored. Overall, higher scores indicate better illness-related couple communication. The scale is presented in Appendix A.

\section{Phase 2: Psychometric evaluation of the CICS}

\section{Participants and Procedure}

The CICS was validated on a sample of patients with ovarian cancer and their partners. Participants were members of an ovarian cancer charity who had expressed willingness to be contacted by third parties. Data was collected as part of a randomized controlled trial assessing the effect of guided written disclosure on distress and quality of life in ovarian cancer patients and their partners (Arden-Close, Gidron, Moss-Morris, \& Bayne, 2008). Eligibility criteria included a diagnosis of ovarian cancer, being no more than 5 years since last treatment (as after this period patients are considered to be disease-free), being over 18 years of age, and ability to communicate in English. Potential participants were sent a letter from the charity director (LB). Interested participants sent the first author (EAC) a slip with their name and telephone number in a stamped addressed envelope. She then telephoned them to assess eligibility, and the initial questionnaire was sent out by post. Those who did not wish to participate were invited to send back a slip indicating the reason for non-participation. The study was also advertised in the charity's newsletter, and on their 
website. Participants were invited to contact the researcher if they were unsure of the meaning of any of the items. Test-retest reliability was assessed at 3 and 6 months for participants in the control group, who had written about their daily activities. The study was approved by the University of Southampton School of Psychology ethics committee.

Three hundred and thirty six patients indicated receipt of the invitation letter. Of these, 203 expressed interest in the study, and 141 were found to be eligible. Reasons for ineligibility included being too long since last treatment (34 participants) and being single (28 participants). A sample of 124 women with ovarian cancer and the partners of 102 patients completed the scale at baseline. This represents a response rate of $88 \%$ of those eligible for patients and $72 \%$ of those eligible for partners. .

\section{Measures}

The questionnaire battery consisted of the CICS and the following self-report measures used to assess the validity of the questionnaire:

\section{Demographic Information}

Questions were designed to elicit basic demographic and disease-related information, such as time since diagnosis, time since treatment, educational level and employment status.

ENRICH Couple Scales communication subscale: This is a 10-item measure of couple communication that has been widely used in the general population (Fowers \& Olson, 1989). It has high reliability, and was found to discriminate distressed and non-distressed couples with over $85 \%$ accuracy in a sample of 5039 couples. This scale was used to determine convergent validity, and was expected to correlate highly with the CICS.

Social/family well-being: This is a 7-item (cancer patients) or 5-item (general population) subscale from the Functional Assessment of Cancer Therapy. This scale has good reliability and validity both in ovarian cancer patients (Basen-Engquist et al., 2001) and in the general population (Cella et al., 2003). It was expected that better social well-being 
would be associated with better illness-related couple communication. This scale was used to determine construct validity.

Intrusive thoughts: Patients and partners completed the Impact of Event scale (intrusions subscale) with regard to the patient's cancer. This scale has good reliability and validity (Weiss \& Marmar, 1997). As social constraint has been associated with increased intrusive thoughts (Lepore et al., 1996), it was expected that higher levels of intrusive thoughts would be associated with worse illness-related couple communication. As partners are generally considered to be close confidants (Harrison, Maguire, \& Pitceathly, 1995), poor illness-related couple communication can be viewed as a form of social constraint. This scale was used to determine construct validity.

Emotional impact of the illness: Patients and partners completed the emotional representations of illness scale from the Illness Perception Questionnaire-Revised, with regard to the patient's cancer. This scale has good reliability and validity in a number of illnesses (Moss-Morris et al., 2002). It was expected that higher levels of emotional impact would be associated with worse illness-related couple communication. This scale was used to determine construct validity.

\section{Criterion Validity}

It was expected that communication about the illness would be more highly associated with distress in partners of patients with recurrent disease, as the illness plays a more central role in their lives. Thus, analyses were carried out to see whether the relation between illnessrelated communication and psychological distress varied depending on recurrence status.

\section{Statistical analyses}

Statistical analyses were conducted using SPSS for Windows (version 15). Pearson correlations were computed to assess test-retest reliability and inter and intra-item correlations. A combination of multiple regressions and correlations were computed to 
assess whether the relations between illness-related couple communication and psychological variables differed depending on recurrence status. Cronbach Alpha was computed to assess internal consistency.

\section{Results}

Baseline demographic and illness data are reported in Table 1.

\section{Psychometric Properties of the CICS}

Overall means and standard deviations of the samples

The mean score on the CICS was $13.84(\mathrm{sd}=3.83$ ) for patients, and 15.53 (sd = 3.21) for their partners. Patients reported poorer illness-related communication than their partners $(\mathrm{t}(221)=3.59, \mathrm{p}<.001)$

Reliability and inter-item correlations

\section{Internal consistency}

Cronbach’s alpha at baseline was 0.84 for patients, and 0.80 for their partners, indicating good reliability. This was not affected by removal of any of the items.

Inter-item correlations

Correlations between items on the CICS ranged from $r=.49$ to $r=.64$ for patients and from $r=.33$ to $r=.59$ for partners.

\section{Test-retest reliability}

All participants who remained in the study completed the questionnaires at 3 and 6 month follow-ups. However, only data from the control group are reported here, due to the possible influence of the intervention on responses. Test-retest reliability over a 3-month period (3-month follow-up to 6-month follow-up) was calculated for the control group. This period was chosen as time since the intervention had increased, thus reducing the possibility 
of a placebo effect contaminating the results. It was found to be 0.71 for patients $(n=52)$ and 0.75 for partners $(n=40)$, indicating acceptable reliability given the time span and clinical circumstances.

Validity

Face validity, content validity and reading ease.

All questions were found to be acceptable, and feedback showed that participants understood the items. Reading ease was at Flesch-Kincaid Grade Level 7 (Microsoft Word Readability Statistics). Since the CICS consists of only 4 items, it is not time-consuming to complete.

\section{Convergent Validity}

This scale was highly correlated with the ENRICH Couple Scales communication subscale (Fowers \& Olson, 1989: $\mathrm{r}=.78, \mathrm{p}<.001$ for patients, and $\mathrm{r}=.69, \mathrm{p}<.001$ for partners.

\section{Construct Validity}

It was hypothesized that better social quality of life would be associated with better illness-related couple communication, whereas higher levels of intrusive thoughts, emotional representations indicative of more distress about the illness, and higher levels of psychological distress would be associated with worse illness-related couple communication. These correlations are reported in Table 2. Illness-related communication was associated with social quality of life in both patients and their partners, and intrusive thoughts and distress about the illness in patients only. Length of marriage was not associated with illnessrelated communication.

\section{Criterion Validity}

Multiple regressions with the psychosocial measure as the outcome variable were carried out to test whether the relations between illness-related communication and 
psychological distress varied depending on disease-related factors such as recurrence status. It was expected that illness-related communication would be more strongly associated with distress in partners whose wives had experienced a recurrence. The intrusive thoughts scale was taken as a representative example of psychological distress, based on previous research (Lepore et al., 1996). Age and disease stage were entered on the first step, the centred illness-related communication score and the disease-related variable (recurrence status) were entered on the second step, and the product of the centred illness-related communication score and the disease-related variable (the interaction term) was entered on the third step. In partners, the interaction between recurrence status and illness-related communication explained $5.8 \%$ of the variance in intrusive thoughts $(F(1,93)=6.71, \mathrm{p}=.01)$. These results are reported in Table 3.

Illness-related communication was not associated with levels of intrusive thoughts in partners whose wives had not experienced a recurrence, but better illness-related communication was associated with fewer intrusive thoughts in partners whose wives had had a recurrence. This information is presented in Figure 1. However, the relation between illness-related communication and intrusive thoughts was not influenced by recurrence status in patients $(F(1,93)=.02, \mathrm{p}=.88)$. These results are reported in Table 4 .

\section{Predictive Validity}

Analyses were carried out to test the relation between illness communication at baseline and the psychosocial variables of emotional representations of the illness, social/ family well-being and intrusive thoughts at three month follow-up. Due to the possible influence of the intervention on response at follow-up, these analyses were based on data from the control group only. In patients, illness-related communication at baseline was 
associated with emotional representations of the illness at three months $(r=-.38, p=.005)$. No other outcomes were found to be significantly predicted by baseline CICS in either gender.

\section{Discussion}

This study provides evidence that the CICS meets the majority of current methodological standards for acceptability, validity and internal consistency in a sample of ovarian cancer patients and their partners. Acceptable test-retest reliability was demonstrated, although it was lower in patients than in partners. However, given the threat to patients' lives and clinical changes in their disease (some experienced a recurrence between baseline and follow-up), these lower estimates were expected.

Study 2

Method

\section{Participants and Procedure}

Participants were drawn from the MS service for two large NHS trusts in the South of England. Data was collected as part of a randomized controlled trial of cognitive-behavioural therapy for adjustment to early stage MS (Moss-Morris et al., personal communication). Eligibility criteria included having a confirmed diagnosis of MS from a neurologist, according to the McDonald criteria (McDonald et al., 2001) within the past ten years, an Expanded Standard Disability Status (EDSS; Kurtzke, 1983) score of 6.5 or less (indicative of the ability to walk short distances), and a score of 20 or above on the Telephone Interview for Cognitive Status-Modified (Brand et al., 1993). Potential patients were provided with information about a trial for adjustment to early stage MS by their specialist nurses or neurologists during clinic appointments and invited to contact the third author (LD) for further information. The study was also advertised on the MS Society website. The study 
was approved by Thames Valley multi-centre research ethics committee.

One hundred and sixty one people returned contact details forms to express an initial interest in the research and of these 112 consented to participate. However, 10 either changed their mind or could not be contacted for screening and enrolment, and 8 were found to be ineligible, so 94 ultimately entered the trial. This represents a response rate of $91 \%$ of those eligible.

\section{Measures}

The questionnaire battery consisted of the CICS and the following self-report measures used to assess the validity of the questionnaire:

\section{Demographic Information}

Questions were designed to elicit basic demographic and disease-related information, such as time since diagnosis, time since treatment, educational level and employment status. Expanded Standard Disability Scale (EDSS): This is a self-administered questionnaire to determine the physical status of patients with multiple sclerosis. Strength, coordination, sensation, bowel function, bladder function, speech, swallowing and cognition are assessed. Intraclass correlations between self- and physician-administered EDSS scores are high. This was included as a covariate in all analyses, in order to determine the impact of illness communication on distress after controlling for disability levels.

Dyadic Adjustment Scale (DAS-4): This is a 4-item measure of marital satisfaction. It has high levels of reliability and discriminates distressed and nondistressed spouses with over 85\% accuracy (Sabourin, Valois, \& Lussier, 2005). Higher scores are indicative of worse marital adjustment. Since communication is an important aspect of marital satisfaction, and this scale has demonstrated sensitivity to changes in couple communication (Yalcin \& Karahan, 2007) this scale was expected to be highly correlated with the CICS. This scale was used to determine convergent validity.

General Health Questionnaire (GHQ-12): This is a twelve item scale that was designed to 
detect psychiatric disorder in people in community and medical settings. Validity and reliability are high (Goldberg, 1992). It was expected that higher scores (indicative of more distress) would be associated with worse illness-related couple communication. This scale was used to determine construct validity.

\section{Criterion Validity}

Based on previous research (Harrison, Maguire, \& Pitceathly, 1995), it was expected that illness-related communication would play a more important role in adjustment for male patients than female patients. Consequently, it was decided to run the correlations by gender.

$$
\text { Results }
$$

\section{Psychometric Properties of the CICS}

Baseline demographic and illness data from all patients who were married or living with a partner was included $(\mathrm{n}=64)$. This is reported in Table 5.

\section{Reliability and inter-item correlations}

\section{Means and Standard Deviations}

The mean score on the CICS was 13.61 (sd = 3.91) for MS patients. The difference between ovarian cancer patients and MS patients was not statistically significant (t (37) = $0.10, \mathrm{p}=.92)$.

\section{Internal Consistency}

Cronbach's alpha was 0.80 , indicating good reliability. This was not affected by removal of any of the items.

\section{Inter-item correlations}

Correlations between items on the CICS ranged from $r=.31$ to $r=.58$. Validity

This sample provided the opportunity to look at the relations between CICS and 
outcome even when controlling for severity of illness. Consequently, all correlations were carried out after controlling for EDSS status, in order to estimate the impact of the illness on illness-related couple communication and distress.

\section{Convergent Validity}

Scores on the CICS were highly correlated with those of the Dyadic Adjustment Scale (DAS-4) (Sabourin et al., 2005) as expected: $\mathrm{r}=-. .63$, $\mathrm{p}<.001$.

\section{Construct Validity}

Illness-related communication was associated with psychological distress $(r=-0.25$, $\mathrm{p}=.048)$.

\section{Criterion Validity}

Pearson correlations between the CICS and the other measures were carried out separately for male and female patients. This tested whether illness-related communication impacted more on distress and marital satisfaction in men or women. While marital adjustment was associated with illness-related communication in both genders, the correlation between psychological distress and illness-related communication was much higher in male patients. These results are reported in Table 6.

\section{Discussion}

This study provides evidence that the CICS meets current methodological standards for internal consistency and validity in a sample of patients with multiple sclerosis. In addition, evidence from the analyses by gender demonstrated that illness-related communication may be a more important determinant of well-being in male patients than female patients.

\section{General Discussion}

This study provides evidence that the CICS meets the majority of current 
methodological standards for acceptability, validity and internal consistency in both a lifethreatening disease (ovarian cancer) and a chronic progressive disease (multiple sclerosis).

The CICS provides insight into both patients' and their partners' willingness to discuss the patient's illness, from patient and partner perspectives. This is important as perceptions of partners' willingness to discuss the illness are likely to influence how often the couple address illness-related issues, which has been correlated with levels of distress in patients (Manne, 1999; Manne et al., 2006).

Evidence for the construct validity of the CICS was provided by highly significant correlations with the ENRICH couple scales communication subscale, and the Dyadic Adjustment Scale. In addition, the CICS appears to be associated with adaptation in both ovarian cancer and multiple sclerosis, even when disease severity is taken into account. Significant positive correlations were found between the CICS and social / family well-being in ovarian cancer patients and their partners, between the CICS and illness-related intrusive thoughts and distress in ovarian cancer patients, and between the CICS and psychological distress in the MS sample.

However, the correlations tended to be moderate at best. It is important to remember there are many other factors that influence social quality of life, such as support from friends and other family members, and physical intimacy. Evidence from the discriminant validity analyses by gender suggests that illness-related couple communication may be a more important correlate of well-being in men than women. In support of this idea, a study of 520 recently diagnosed cancer patients found that men tended to name only one confidant, their spouse, whereas women had a wider circle of family and friends to whom they confided information about their cancer (Harrison et al., 1995). It is possible that illness-related communication with friends and relatives may compensate for lack of communication about the illness with partners, in women. Certainly, Helgeson, Cohen, Schulz, and Yasko (2000) 
found that a peer discussion group was helpful for breast cancer patients who lacked support from their partners. Asking women to complete the scale with reference to a close person other than their partner, would enable testing of this hypothesis.

However, the evidence from the ovarian cancer sample that illness-related communication at baseline was associated with emotional representations of the illness at three month follow-up suggests that inability to discuss the illness with partners may lead to more illness-specific distress in the long-term. This finding agrees with that of Pistrang and Barker (1995) that partner support cannot always be compensated for by support from other individuals. Illness-related communication may be best assessed soon after diagnosis in order to enable early communication interventions if appropriate.

The CICS was related to illness-related intrusive thoughts in patients but not partners. This finding is in line with research showing that avoidance of discussing illness-related issues is more detrimental to well-being for patients than for partners (Manne et al., 2007). Length of marriage was not correlated with illness-related couple communication. This finding suggests that all couples should be assessed for illness-related communication, regardless of the length of their marriages.

As evidence that the severity or life threatening nature of the illness influences the relation between psychosocial factors and illness-related communication, the CICS was associated with intrusive thoughts in partners of ovarian cancer patients only if the patients had recurrent disease. Illness-related communication can be conceived as a form of social support, and the recurrence of cancer as a severe stressor. This CICS by recurrence interaction could be seen as support of the buffering hypothesis of stress and social support (Cohen et al., 1985). The recurrence of an illness is expected to yield more intrusive thoughts, possibly moderated by better illness-related communication. However, there was no such interaction in patients. As over 99\% of partners in the ovarian cancer sample were men (only 
one same sex couple participated), this finding is in line with the analyses by gender in the sample of MS patients showing that illness-related communication may be a more important correlate of well-being in men than women.

Finally, if couples were found to have poor illness-related communication, Skerrett (2003) has developed a three-step process designed to facilitate a 'couple’ mindset, based on couple therapy. This involves building 'we' awareness, building awareness of the illness stories, and nourishing the 'we' (for further details see Skerrett, 2003). However, as this approach is likely to be time-consuming, further research is needed to develop briefer interventions.

A number of methodological limitations need consideration. Different measures were used for the ovarian cancer and the MS samples. While this enabled validation of the CICS against more measures, it did not allow direct comparisons to be made between the samples. This might have highlighted differences in responses to chronic versus life-threatening illnesses. For the ovarian cancer sample, it was not possible to gain information about nonresponders, limiting the generalisability of our findings. A number of those who were unwilling to participate may have been ineligible due to length of time since their last treatment or being single. The analyses by gender were based on small numbers, and thus should be regarded as exploratory. In this study all the cancer patient sample and the majority of the MS patient sample were female. Further research is needed to assess the extent to which the CICS generalizes to couples where the husband/male partner is the patient. Furthermore, the current samples consisted of over 99\% heterosexual couples, and the vast majority of participants were white British. Further research is needed to examine the extent to which the CICS generalizes to single-sex couples, and to other cultures.

\section{Conclusions}


This study provides evidence for the acceptability, reliability and validity of the CICS to assess illness-related couple communication in a sample of patients with a life-threatening illness and their partners and in a sample of patients with a chronic progressive disease. The CICS is a short, easy to administer questionnaire that could be easily adapted to routine care. The data presented here suggest that illness-related communication is a significant predictor of adjustment to illness. Understanding illness-related communication is important in order to determine ways to improve couple communication when one partner has a chronic illness. The CICS could be used in future research and clinical practice when attempting to assess illness-related communication and related outcomes.

Acknowledgments: The authors would like to thank Angeliki Bogosian, Bina Nausheen and Katarzyna Zinken for their comments on an earlier draft of this article. 


\section{Appendix}

\section{$\underline{\text { CICS - Patient version }}$}

The following questions ask about your relationship with your partner. Each question should be answered on the scale shown below.

$\begin{array}{lllll}1 & 2 & 3 & 4 & 5 \\ \text { Disagree } & \text { Disagree } & \text { Undecided } & \text { Agree } & \text { Agree } \\ \text { Strongly } & & & & \text { Strongly }\end{array}$

1. It is hard for me to express feelings about my illness to my partner.

2. I feel comfortable discussing issues related to my illness with my partner.

3. My partner is reluctant to talk about my illness.

4. My partner is willing to share his/her feelings about my illness with me.

\section{CICS - Partner version}

The following questions ask about your relationship with your partner. Each question should be answered on the scale shown below.
1
2
3
4
5
Disagree
Disagree
Undecided
Agree
Agree
Strongly
Strongly

5. It is hard for me to express feelings about his/her illness to my partner.

6. I feel comfortable discussing issues related to his/her illness with my partner.

7. My partner is reluctant to talk about his/her illness.

8. My partner is willing to share his/her feelings about his/her illness with me. 


\section{Reference List}

Arden-Close, E., Gidron, Y., Moss-Morris, R., \& Bayne, L. (2008). Effects of guided written disclosure on wellbeing in ovarian cancer patients and their partners (abstract). Psychology and Health, 23, 56-57.

Basen-Engquist, K., Bodurka-Bevers, D., Fitzgerald, M. A., Webster, K., Cella, D., Hu, S. et al. (2001). Reliability and validity of the Functional Assessment of Cancer Therapy - Ovarian. Journal of Clinical Oncology, 19, 1809-1817.

Berg, C. A. \& Upchurch, R. (2007). A developmental-contextual model of couples coping with chronic illness across the lifespan. Psychological Bulletin, 133, 920-954.

Boehmer, U. \& Clark, J. A. (2001). Communication about prostate cancer between men and their wives. Journal of Family Practice, 50, 226-231.

Bogosian, A., Moss-Morris, R., Yardley, L., \& Dennison, L. (2009). Experiences of partners of people in the early stages of multiple sclerosis. Multiple Sclerosis.

Brandt, J., Welsh, K., Breitner, J., Folstein, M., Helms, M., \& Christian, J. (1993). Hereditary influences on cognitive functioning in older men; a study of 4000 pairs. Archives of Neurology, 50, 599-603.

Cella, D., Zagari, M. J., Vandoros, C., Gagnon, D. D., Hurtz, H. J., \& Nortier, J. W. R. (2003). Epoetin alfa treatment results in clinically significant improvements in quality of life in anemic cancer patients when referenced to the general population. Journal of Clinical Oncology, 21, 366-373.

Christensen, A. (1988). Dysfunctional interaction patterns in couples. In P.Noller \& M. A. Fitzpatrick (Eds.), Perspectives on marital interaction (pp. 30-52). Philadelphia: Multilingual Matters.

Cohen, M., Hoffman, R. G., Cromwell, C., Schmeidler, J., Ebrahim, F., Carrera, G. et al. (2002). The prevalence of distress in persons with human immunodeficiency virus infection. Psychosomatics, 43, 10-15.

Cohen, S., \& Wills, T.A. (1985). Stress, social support, and the buffering hypothesis. Psychological Bulletin 98, 310-357. 
Eriksson, M. \& Svedlund, M. (2006). 'The intruder': Spouses' narratives about life with a chronically ill partner. Journal of Clinical Nursing, 15, 324-333.

Fowers, B. J. \& Olson, D. H. (1989). ENRICH Marital Inventory - A Discriminant Validity and Cross-Validity Assessment. Journal of Marital and Family Therapy, 15, 65-79.

Gessler, S., Low, J., Daniells, E., Williams, R., Brough, V., Tookman, A. et al. (2008). Screening for distress in cancer patients: Is the distress thermometer a valid measure in the UK and does it measure change over time? A prospective validation study. Psycho-Oncology, 17, 538-547.

Goldberg, D. (1992). General Health Questionnaire (GHQ-12). Windsor: NFER-NELSON.

Goodkin D. (1998) Interferon beta therapy for multiple sclerosis. Lancet, 352, 1486-7.

Graham, J. (2002). What is MS? MS Society; UK.

Harrison, J., Maguire, P., \& Pitceathly, C. (1995). Confiding in crisis: Gender differences in pattern of confiding among cancer patients. Social Science and Medicine, 41, 1255-1260.

Helgeson, V. S., Cohen, S., Schulz, R., \& Yasko, J. (2000). Group support interventions for women with breast cancer: Who benefits from what? Health Psychology, 19, 107-114.

Holmberg, S. K., Scott, L. L., Alexy, W., \& Fife, B. L. (2001). Relationship issues of women with breast cancer. Cancer Nursing, 24, 53-60.

Kayser, K., Watson, L. E., \& Andrade, J. T. (2007). Cancer as a "We-disease".: Examining the process of coping from a relational perspective. Families, Systems, and Health, 25, 404-418.

Kurtzke, J. (1983). Rating neurological impairment in multiple sclerosis: an expanded disability status scale (EDSS). Neurology, 33, 1444-1452.

Lepore, S.J., Silver, R.C., Wortman, C.B., \& Wayment, H.A. (1996). Social constraints, intrusive thoughts, and depressive symptoms among bereaved mothers. Journal of Personality and Social Psychology, 70, 271-282.

Manne, S., Ostroff, J., Sherman, M., Heyman, R. E., Ross, S., \& Fox, K. (2004). Couples' support-related communication, psychological distress, and relationship satisfaction among women with early stage breast cancer. Journal of Consulting and Clinical Psychology, 72, 660-670. 
Manne, S. L. (1999). Intrusive thoughts and psychological distress among cancer patients: The role of spouse avoidance and criticism. Journal of Consulting and Clinical Psychology, 67, 539546.

Manne, S. L., Norton, T. R., Ostroff, J. S., Winkel, G., Fox, K., \& Grana, G. (2007). Protective buffering and psychological distress among couples coping with breast cancer: The moderating role of relationship satisfaction. Journal of Family Psychology, 21, 380-388.

Manne, S. L., Ostroff, J. S., Norton, T. R., Fox, K., Goldstein, L., \& Grana, G. (2006). Cancer-related relationship communication in couples coping with early stage breast cancer. PsychoOncology, 15, 234-247.

McDonald, W. I., Compston, A., Edan, G., Goodkin, D., Hartung, H. P., Lublin, F. D. et al. (2001). Recommended diagnostic criteria for multiple sclerosis: Guidelines from the International Panel on the Diagnosis of Multiple Sclerosis. Annals of Neurology, 50, 121-127.

Mitchell, A. J. (2007). Pooled results from 38 analyses of the accuracy of distress thermometer and other ultra-short methods of detecting cancer-related mood disorders. Journal of Clinical Oncology, 25, 4670-4681.

Mohr, D. C. \& Cox, D. (2001). Multiple Sclerosis: Empirical Literature for the Clinical Health Psychologist. Journal of Clinical Psychology, 57, 479-499.

Moss-Morris, R. Dennison, L., Yardley, L., Landau, S., Roche, S., McCrone, P., \& Chalder, T. (2009). Protocol for the saMS trial (supportive adjustment for multiple sclerosis): A randomized controlled trial comparing cognitive behavioral therapy to supportive listening for adjustment to multiple sclerosis. BMC Neurology, 9, 45.

Moss-Morris, R., Weinman, J., Petrie, K. J., Horne, R., Cameron, L. D., \& Buick, D. (2002). The revised Illness Perception Questionnaire (IPQ-R). Psychology \& Health, 17, 116.

National MS Society (2008). Who gets MS? Retrieved May 20, 2008, from: http://www.nationalmssociety.org/about-multiple-sclerosis/who-getsms/index.aspx

Pistrang, N. \& Barker, C. (1995). The partner relationship in psychological response to breast cancer. Social Science and Medicine, 40, 789-797. 
Rohrbaugh, M.J., Mehl, M.R., Shoham, V., Reilly, E.S., \& Ewy, G.A. (2008). Prognostic significance of spouse we talk in couples coping with heart failure. Journal of Consulting and Clinical Psychology, 76, 781-789.

Sabourin, S., Valois, P., \& Lussier, Y. (2005). Development and validation of a brief version of the Dyadic Adjustment SCale with a nonparametric item analysis model. Psychological Assessment, 17, 15-27.

Skerrett, K. (2003). Couple dialogues with illness: Expanding the "We". Families, Systems, and Health, 21, 49-60.

Skerrett, K. (1998). Couple adjustment to the experience of breast cancer. Families, Systems, and Health, 16, 281-298.

Walters, S., Rachet, B., Westlake, S., Cooper, N., Rasulo, D., Horn, O., et al. (2009). Cancer survival, England, patients diagnosed 2001-2006 and followed up to 2007: one-year and five-year survival for 21 common cancers, by sex and age. Office for National Statistics website: http://www.statistics.gov.uk/downloads/theme_health/cancer-survival-Eng-20012006.pdf

Weiss, D. \& Marmar, C. (1997). The Impact of Event Scale - Revised. In J.Wilson \& T. Keane (Eds.), Assessing Psychological Trauma and PTSD ( New York: Guildford.

Yalcin, B.M., \& Karahan, T.F. (2007). Effects of a couple communication program on marital adjustment. Journal of the American Board of Family Medicine, 20, 36-44. 
Table 1: Baseline demographic and illness characteristics of the ovarian cancer patients and their partners

\begin{tabular}{|c|c|c|c|}
\hline Participant & & Patients & Partners \\
\hline Characteristics & & $\mathrm{N}=123$ & $\mathrm{~N}=101$ \\
\hline Age (Mean, range) & & $55.7(27-76)$ & $57.8(34-79)$ \\
\hline Disease stage: & Early & $44(35 \%)$ & \\
\hline & Advanced & 79 (65\%) & \\
\hline Time since diagnosis in & & $37(4-186)$ & \\
\hline months (Mean, range) & & & \\
\hline Time since last treatment & & $15(0-60)$ & \\
\hline in months (Mean, range) & & & \\
\hline Currently having & & $21(17 \%)$ & \\
\hline treatment & & & \\
\hline Number of courses of & & $1.5(0-5)$ & \\
\hline chemotherapy (Mean, & & & \\
\hline range) & & & \\
\hline Length of time married/ & & $27.9(1-54)$ & \\
\hline living with partner in & & & \\
\hline years (Mean, range) & & & \\
\hline Highest level of & GCSE or below & 44 (36.1\%) & $24(24.4 \%)$ \\
\hline & A-level/ & 38 (31.1\%) & $33(32.6 \%)$ \\
\hline & technical & & \\
\hline & qualification & & \\
\hline & Tertiary education & 40 (32.8\%) & 43 (43\%) \\
\hline
\end{tabular}


Table 2: Matrix of correlations between scores on the CICS and other psychosocial/ demographic measures, after controlling for disease stage - ovarian cancer patients and their partners

\begin{tabular}{lll}
\hline Variable & CICS (Patients) & CICS (Partners) \\
\hline Social/family well-being & $0.46^{* *}$ & $0.36^{* *}$ \\
(FACT) & & \\
Intrusive thoughts (IES) & $-0.27^{* *}$ & -0.10 \\
Emotional impact of the illness & $-0.22^{*}$ & -0.14 \\
Time married (years) & -0.06 & 0.08 \\
\hline
\end{tabular}

$* * \mathrm{p}<.01 * \mathrm{p}<.05$ (2-tailed) 
Table 3: Multiple regression of predictors of intrusive thoughts in partners of patients with ovarian cancer

\begin{tabular}{|c|c|c|c|c|}
\hline & Variable & $\bar{B}$ & $\begin{array}{l}\text { Standard } \\
\text { error b }\end{array}$ & Beta \\
\hline \multirow[t]{3}{*}{ Step 1} & Constant & 4.86 & 4.08 & \\
\hline & Age & -0.02 & 0.07 & -0.02 \\
\hline & Disease stage & 1.92 & 0.78 & $0.25 *$ \\
\hline \multirow[t]{6}{*}{ Step 2} & Constant & 17.69 & 6.34 & \\
\hline & Age & -0.39 & 0.07 & -0.06 \\
\hline & Disease stage & 1.02 & 0.84 & 0.13 \\
\hline & Recurrence & -3.84 & 1.46 & $-0.28 * *$ \\
\hline & Illness & -0.21 & 0.22 & -0.10 \\
\hline & communication & & & \\
\hline \multirow[t]{7}{*}{ Step 3} & Constant & 45.58 & 12.40 & \\
\hline & Age & -0.03 & 0.07 & -0.04 \\
\hline & Disease stage & 1.05 & 0.81 & 0.14 \\
\hline & Recurrence & -3.59 & 1.42 & $-0.26^{*}$ \\
\hline & Illness & -2.08 & 0.76 & $-0.96 * *$ \\
\hline & communication & & & \\
\hline & Interaction & 1.12 & 0.43 & $0.90 *$ \\
\hline
\end{tabular}


Table 4: Multiple regression of predictors of intrusive thoughts in patients with ovarian cancer

\begin{tabular}{|c|c|c|c|c|}
\hline & Variable & B & $\begin{array}{c}\text { Standard } \\
\text { error b }\end{array}$ & Beta \\
\hline \multirow[t]{3}{*}{$\overline{\text { Step } 1}$} & Constant & 19.50 & 4.52 & \\
\hline & Age & -0.20 & 0.08 & $-0.25^{*}$ \\
\hline & Disease stage & 0.94 & 0.82 & 0.12 \\
\hline \multirow[t]{6}{*}{ Step 2} & Constant & 35.73 & 6.33 & \\
\hline & Age & -0.21 & 0.08 & $-0.26^{*}$ \\
\hline & Disease stage & 0.18 & 0.81 & 0.02 \\
\hline & Recurrence & -3.21 & 1.55 & $-0.21^{*}$ \\
\hline & Illness & -0.64 & 0.19 & $-0.32 * *$ \\
\hline & communication & & & \\
\hline \multirow[t]{7}{*}{ Step 3} & Constant & 34.42 & 10.82 & \\
\hline & Age & -0.21 & 0.08 & $-0.26^{*}$ \\
\hline & Disease stage & 0.17 & 0.81 & 0.02 \\
\hline & Recurrence & -3.20 & 1.56 & $-0.21^{*}$ \\
\hline & Illness & -0.54 & 0.67 & -0.27 \\
\hline & communication & & & \\
\hline & Interaction & -0.06 & 0.39 & -0.05 \\
\hline
\end{tabular}


Table 5: Baseline demographic and illness characteristics of the MS patients

\begin{tabular}{|c|c|c|}
\hline Participant Characteristics & $n=64)$ & Descriptive statistics \\
\hline Age (mean, range) & & $42.1(23-66)$ \\
\hline \multirow[t]{2}{*}{ Gender } & Female & $44(68.8 \%)$ \\
\hline & Male & $20(32.2 \%)$ \\
\hline EDSS status (mean, range) & & $4.7(0-6.5)^{*}$ \\
\hline Time since diagnosis & & $49(1-132)$ \\
\hline \multicolumn{3}{|l|}{ (months) } \\
\hline Relapses in past year & & $1.2(0-4)$ \\
\hline \multicolumn{3}{|l|}{ (mean, range) } \\
\hline \multirow[t]{4}{*}{ MS type } & Relapsing remitting & 46 (71.9\%) \\
\hline & Primary progressive & $8(12.5 \%)$ \\
\hline & Secondary progressive & $4(6.3 \%)$ \\
\hline & Don’t know & $6(9.4 \%)$ \\
\hline \multirow[t]{4}{*}{ Educational level } & GCSE or below & $21(32.8 \%)$ \\
\hline & A-level/ technical & $13(20.3 \%)$ \\
\hline & qualification & \\
\hline & Tertiary education & $30(46.9 \%)$ \\
\hline
\end{tabular}

* This is indicative of the ability to walk without aid or rest for 200 metres, and impairment of daily activities. 
Table 6: Matrix of correlations between scores on the CICS and other psychosocial measures, after controlling for EDSS status - MS patients

\begin{tabular}{lllll}
\hline Variable & Overall & Men & Women & Statistical \\
& $(\mathrm{N}=64)$ & $(\mathrm{n}=20)$ & $(\mathrm{n}=44)$ & comparison \\
\hline Marital Adjustment (DAS-4) & $-0.63^{* *}$ & $-0.80^{* *}$ & $-0.58^{* *}$ & $\chi^{2}=1.53$ \\
& & & & $(\mathrm{p}=.13)$ \\
Psychological Distress (GHQ) & $-0.25^{*}$ & $-0.66^{* *}$ & -0.09 & $\chi^{2}=2.45$ \\
& & & & $(\mathrm{p}=.01)$ \\
\hline$* * \mathrm{p}<.01,{ }^{*} \mathrm{p}<.05$ (2-tailed) & & & &
\end{tabular}


Figure 1: Effect of the interaction between illness-related communication and recurrence status on predicting intrusive thoughts in partners of ovarian cancer patients

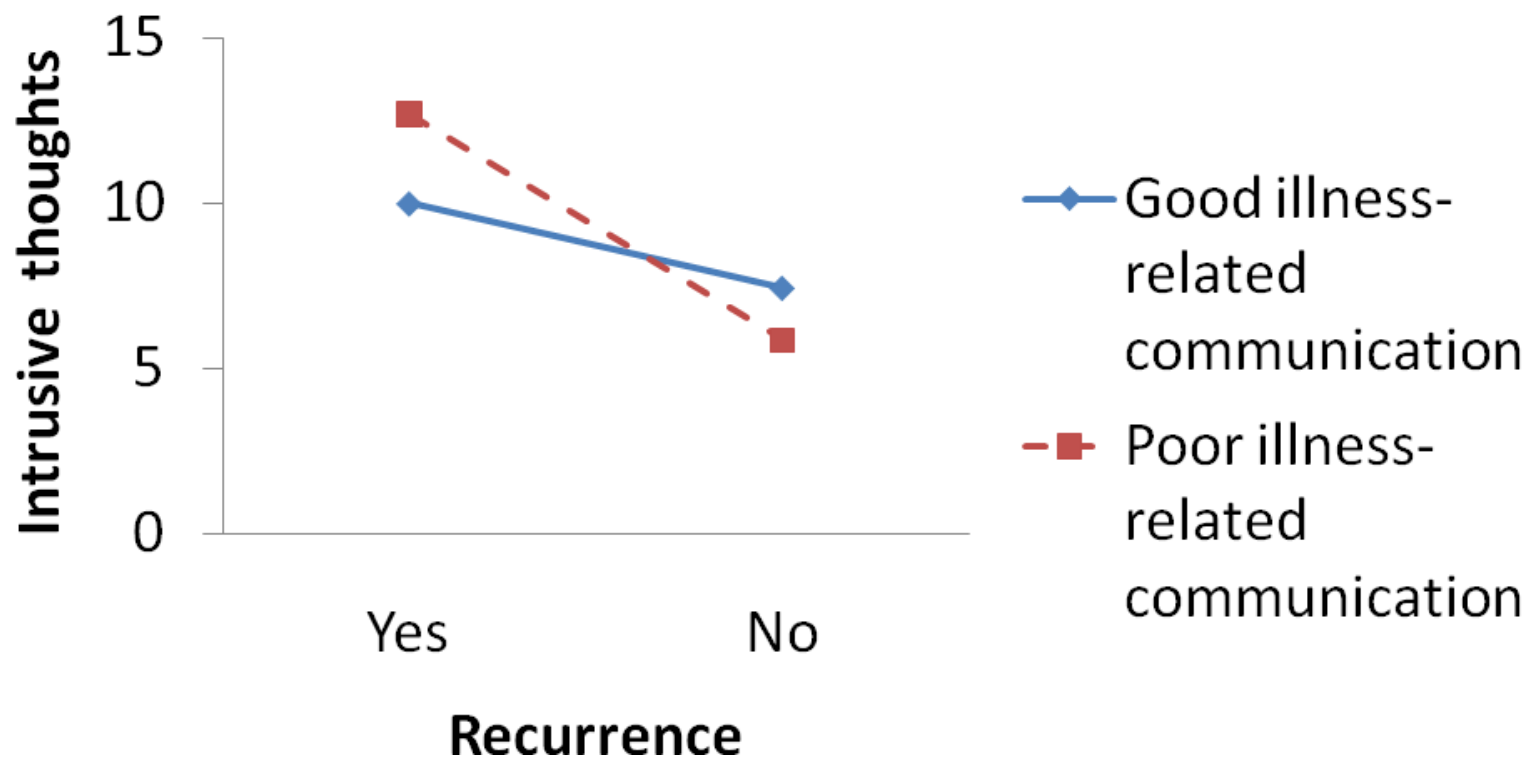




\section{Appendix 1: CICS \\ Couples' Illness Communication Scale \\ CICS - Patient version}

The following questions ask about your relationship with your partner. Each question should be answered on the scale shown below.
1
23
Disagree
Disagree
Undecided
4
5
Strongly
Agree
Agree
Strongly

2. It is hard for me to express feelings about my illness to my partner.

3. I feel comfortable discussing issues related to my illness with my partner.

4. My partner is reluctant to talk about my illness.

5. My partner is willing to share his/her feelings about my illness with me.

\section{CICS - Partner version}

The following questions ask about your relationship with your partner. Each question should be answered on the scale shown below.

$\begin{array}{lllll}1 & 2 & 3 & 4 & 5 \\ \text { Disagree } & \text { Disagree } & \text { Undecided } & \text { Agree } & \text { Agree } \\ \text { Strongly } & & & & \text { Strongly }\end{array}$

6. It is hard for me to express feelings about his/her illness to my partner.

7. I feel comfortable discussing issues related to his/her illness with my partner.

8. My partner is reluctant to talk about his/her illness.

My partner is willing to share his/her feelings about his/her illness with me. 